\title{
Sleep Disturbances among Primi Gravidae
}

\author{
Safaa Abdelaty Goniem, **Galal Ahmed Elkholy, Soad Abd Elsalam Ramadan, and Hend \\ Abd Allah Afifi \\ *Technical Nursing Institute,Faculty of Nursing- Benha University, ** Obstetrics an Gynecology \\ Faculty of Medicine ,Benha University-*** Obstetrics and Woman Health Nursing ,Faculty of \\ Nursing , Benha University.
}

\begin{abstract}
Transition Aim: The current study aimed to identify the patterns of sleep disturbance among primigravidea pregnant mother women and their possible contributing factors. Setting: the study was conducted at ante-natal care out patient clinic at Benha University hospital. Design: A descriptive study design. Sampling: Purposive sample of 200 primigravidae women. Tools:Three tools were used to collect data, structured interviewing questionnaire, (insomnia rating scale, Epworth scale, Berlin scale and leg cramps); factors contributing to sleep disturbances during pregnancy; Pittsburgh Sleep Quality Index. Results:Poor quality of sleep was significantly more common during last trimester among young primigavidae younger than 25 years. Insomnia, day time sleepiness, snoring were the most reported patternsof sleep disturbances followed by breathing disturbances and leg cramps. Patterns of sleep disturbances were statistically significant to demographic characteristics and gestational age of pregnancy $(\mathrm{p}$ $<0.05$ ) Conclusion: poor quality of sleep was prevalent among healthy primigravida women during pregnancy. Insomnia, snoring, breathing disturbances, day time sleepiness and leg cramps are the most common pattern of sleep disturbances among primigravidea. Adverse obstetrical disorders, physical and psychosocial factors are associated with their sleep during pregnancy. $(p<0.05)$. Recommendation: Discussing factors that lead to sleep disturbances should be included in routine antenatal care.
\end{abstract}

Key words: Sleep disturbances, Primigravida.

Introduction

The Pregnancy is associated with many physical, hormonal, and physiological changes which may influence the sleep; pattern of pregnant mother mean while66 to $94 \%$ of women reports sleep disturbances during pregnancy, one manifestation of which is insomnia. The rate of sleep disturbances also changes across trimesters, ranging from $13 \%$ in the first trimester, $19 \%$ in the second and $66 \%$ in the third. At the beginning of pregnancy, the incidence of insomnia is lower at $12.6 \% 7$ and then increases as pregnancy progresses (Hutchison et al., 2012).

Moreover, pregnancy is one of the causes of sleep disturbances. Decreased sleep quality is one of the common complaints during pregnancy; mostly occurring in the third trimester of pregnancy as the women approaches the end of pregnancy while, the incidence of sleep disorders has been reported around $75 \%$ in the third trimester of pregnancy (Golmakani et al ., 2015). 
Sleep disturbances had also been consistently reported during pregnancy such as variations in sleep duration and sleepiness, increase in nocturnal awakenings, snoring and restless legs syndrome, and increase, decrease or stabilization in apnea and hyponea. These disturbances in sleep characteristics progressively increase during pregnancy (O'Brien etal., 2014).

Education of sleep healthy behaviors in conventional prenatal care as a routine disciplinary care plan as well as, an appropriate counseling in this period to prevent sleep disorders is very important to improve maternal health also, for modification of most complaints concerning physical problems disturbing sleep in pregnancy such as nausea, vomiting, headache, excessive sleep and tiredness, heart burn, low back pain, leg cramps, flatulence, constipation, urine frequency, and lack of daily activities due to fear of a miscarriage (Rezaei et al., 2014).

Nurse role in health teaching cannot be over emphasized. Most women don't think about their sleep. This means that they also don't recognize the importance of routine sleep or consider the factors that influence good sleep. In addition there are many myths regarding what constitutes good sleep and what factor contribute to sleep quality. The nurse may also be involved in teaching relaxation techniques such as meditation, guided imagery, progressive muscle relaxation or controlled breathing exercise while the use of these techniques has been linked to sustained benefits of woman with primary insomnia (Spielman et al., 2014).

The nurse should encourage women to develop strategies to improve sleep. Specifically, information on the mechanisms of sleep and the importance of circadian rhythm and how will be provided. Specific attention will be given to the difference between active and quiet sleep. Furthermore, to clarify many misconceptions associated with sleep and in particular, napping.women will have information of how to manage naps in order to improve daytime fatigue without disrupting their subsequent night of sleep (Kempler et al., 2012).

\section{Aim of the study}

The study aimed to:

1- Identify the pattern of sleep disturbances during pregnancy among primigravidea women.

2- Identify the possible contributing factors to sleep disturbances during pregnancy among primigravidea women .

\section{Research questions:-}

- What are the patterns of sleep disturbances among primigravidea?

- What are factors contributing to sleep disturbances during pregnancy among primigravidea women ?

\section{Subjects and Method}

\section{Research Design:}

A descriptive design was used.

\section{Setting of the study:}

The study was conducted at ante natal care out patient clinic at Benha University hospitals.

Sample: purposive sample.

Sample Size: A total of 200primigravidae that meet the inclusion criteria, Pregnant women who are 
Primigravidae, single ton gestation, free from physical and psychiatric illnesses, or taking sedative drugs and complain from sleep disturbances attending to the pre mentiond setting for aperiod of six months.

\section{Tools of data collection:}

Three tools were used for collectingdata:

\section{Tool I: Structured interviewing questionnaire:}

It consists of three parts

Part (1) Socio demographic data included age, level of education, occupation, type of work, residence and the type of family.

Part (2) Anthropometric measurement included weight during pregnancy, height, no result for BMD.

Part (3) Obstetric history to assess obstetric and gynecological historyincluded last menstrual period, current pregnancy duration and the number of fetus.

Par (4) This part consisted of four categories included insomnia rating scale adopted from Douglas et al., (2003), to asses sleep habit, Epworth scale adopted from Johne (2005), to asses day time sleepiness, Berlin scale adopted from Philip (2010), to asses snoring and breathing disturbances and leg cramps.

Tool II: Factors contributing to sleep disturbances during pregnancy

This tool was developed by the researcher after review of current relevant literature Suman, (2014), Gabriel et al.,
(2010) and Da Costa et al., (2010)It consisted of (3) section

- Section (1)physical factor related to sleep disturbances it included (10) items, respiratory distress, uncomfortable position during sleep, back pain and frequent going to bath room at night.

- Section (2) obstetric factors related to sleep disturbances it included (6) items, vaginal infection and itching, contraction of the uterus, vomiting and nausea.

- Section (3)psycho social factors related to sleep disturbances it included (9) items, worries regarding fetus sex, watching television for long time, presence of mother in low at house and negative thinking about labor

Tool III: Pittsburgh Sleep QualityIndex (PSQI) was adopted from Carole, (2007) to measure the quality and patterns of sleep during the previous month. It consisted of (19) statments about the nature of sleep during the past month. PSQI yielded seven domains related to sleep habits, including: subjective sleep quality( 1 statement), sleep latency (2 statement), sleep duration(1 statement), habitual sleep efficiency (2 statement), sleep disturbance(10 statement), sleeping medication(1 statement) and daytime dysfunction (2 statement).

\section{Content validity and reliability:}

The revision of tools was done by a panel of (3) expertise professors of the Obstetric and women health at faculty of Nursing and faculty of Medicine, Benha university to measure the validity of tools and necessary modification was done accordingly. Reliability for factors affecting sleep disturbances during 
pregnancy by Chronbach,s Alpha equal 0.69 , while for sleep disturbances during pregnancy ( Pittsburg scale it is adopted not adpted so it is not indicated for reliability) equal 0.77 .

\section{Ethical considerations:}

- Each woman was informed about the purpose and benefits of the study at the beginning of interview and time throughout the study.

- An oral consent was obtained from each woman before starting data collection.

- Confidentiality was ensured throughout the study process, where personal data were not disclosed, and the women were assured that all data was used only for research purpose.

- Each woman are informed that, participation is voluntary and her withdrawal will not affect her care.

\section{Pilot study:}

- The pilot study was carried out. It involved ten percent from duration (18 day) the pilot study was done $10 \%(\mathrm{n}=20)$, it took a duration of 18 days to be accomplished to test the clarity and applicability of study tools as well as, estimation of the time needed to fill the questionnaire. Required modification was done in the form of omission of some questions. Women involved in the pilot study were excluded from the study.

\section{Field work:}

The field work of the current study was carried out from the beginning of august, 2015 till the end of January 2016 covered six months. The study setting was visited by the researcher 4times/week from $9 \mathrm{Am}$ to $1 \mathrm{Pm}$. At the beginning of the interview took oral consent, for full filling the interviewing questionnaire sheet that, it took about 15 minute. Measuring weight and height, making equation of body mass index (BMI) =weight (in kilogram/height (in meters). assessing factors affecting sleep disturbances such as (physical, obstetric, and psychosocial factors) that, it talk about 15 minutes.

- Pattern of sleep disturbances was assessed by four scales, insomnia rating scale, Epworth scale, Berlin scale and leg cramps scale and measured quality of sleep for primigravidea through Pittsburg sleep quality index which contains (7) domains that took 5-10 minutes. All questions sheet took about 30 45 minutes.

\section{Statistical design:}

- Data was verified prior to computerized entry. The statistical package for social sciences (SPSS version 20). Was used for that purpose, followed by data tabulation and analysis. Descriptive statistics were applied (e.g(mean frequency and SDstandard deviation) frequency and percentages).Test of significance (chi- square) were used.

\section{Results}

Table (1)shows that more than three quarters $(82.5 \%)$ of the studied women were in age group $20<30$ years with mean age $22.3 \pm 2.7$ years, less than half of them $(49.5 \%)$ have university education, less than three quarters $(74.5 \%)$ are unemployed while $(51.5 \%)$ have office work. More than two thirds $(69 \%)$ live in rural areas, half $(50 \%)$ of 
women has nuclear family and half (50\%) has extended family.

Figure (1) concerning the gestation of pregnancy among the studied women illustrates that more than half $(57.5 \%)$ of studied women were in third trimester while, in relation to less than half $(42.5 \%)$ of them were in second trimester of pregnancy.

Figure (2) studied women's sleep was moderately affected by obstetric, physical and psycho social factors $66.5 \%, 60.5 \%$ and $71 \%$ respectively. Meanwhile, $4 \%$ of studied women was highly affected by psycho social factors.

Table (2)Regarding this table shows that, the studied women have average subjective sleep quality, long sleep latency, long sleep duration, low sleep efficacy, sleep disturbances three or more times per week and day time dysfunction $(77 \%, 45 \%, 50.5 \%, 46.5 \%$, $76.5 \%, 100 \%$ and $77.5 \%$ respectively).
Table (3) concerning this table demonstrates that there were statistical significance difference $(\mathrm{P}<0.05)$ between total quality of sleep and (age, educational level, natural of work and address). Mean while there's no statistical significance difference $(p>0.05)$ between total sleep quality and (occupation, type of family). Tables (4) there were statistical significance difference $(\mathrm{p}<$ 0.05 ) between total sleep quality and physical factors affecting sleep disturbances during pregnancy. Mean while there's no statistical significance difference $(p>0.05)$ between total sleep quality and obstetrics, psychological factors.

Table (5) there were difference between second and third trimester as regards insomnia, leg cramps, snoring, total sleep quality and short sleep duration. Meanwhile, there was no difference as regards day time sleep and snoring. 
Table (1): Distribution of studied women according to socio- demographic characteristics.

\begin{tabular}{|c|c|c|}
\hline Socio-demographic characteristics & $\begin{array}{c}\text { No } \\
n=200\end{array}$ & $\%$ \\
\hline \multicolumn{3}{|l|}{ Age (years) } \\
\hline \multirow{3}{*}{$\begin{array}{l}<20 \\
20-<30 \\
30-<40\end{array}$} & 21 & 10.5 \\
\hline & 165 & 82.5 \\
\hline & 14 & 7.0 \\
\hline Mean \pm SD & \multicolumn{2}{|c|}{$22.3 \pm 2.7$} \\
\hline \multicolumn{3}{|l|}{ Educational level } \\
\hline Illiterate & 13 & 6.5 \\
\hline Basic education & 9 & 4.5 \\
\hline Secondary education & 79 & 39.5 \\
\hline University education & 99 & 49.5 \\
\hline \multicolumn{3}{|l|}{ Occupation } \\
\hline $\begin{array}{l}\text { Employed } \\
\text { Unemployed }\end{array}$ & $\begin{array}{c}51 \\
149\end{array}$ & $\begin{array}{l}25.5 \\
74.5\end{array}$ \\
\hline \multicolumn{3}{|l|}{ Nature of work $(n=51)$} \\
\hline $\begin{array}{l}\text { Office work } \\
\text { Hard work }\end{array}$ & $\begin{array}{l}36 \\
15\end{array}$ & $\begin{array}{l}70.6 \\
29.4\end{array}$ \\
\hline \multicolumn{3}{|l|}{ Residence } \\
\hline $\begin{array}{l}\text { Rural } \\
\text { Urban }\end{array}$ & $\begin{array}{c}138 \\
62\end{array}$ & $\begin{array}{l}69.0 \\
31.0\end{array}$ \\
\hline \multicolumn{3}{|l|}{ Type of family } \\
\hline $\begin{array}{l}\text { Nuclear family } \\
\text { Extended family }\end{array}$ & $\begin{array}{l}100 \\
100\end{array}$ & $\begin{array}{l}50.0 \\
50.0\end{array}$ \\
\hline
\end{tabular}

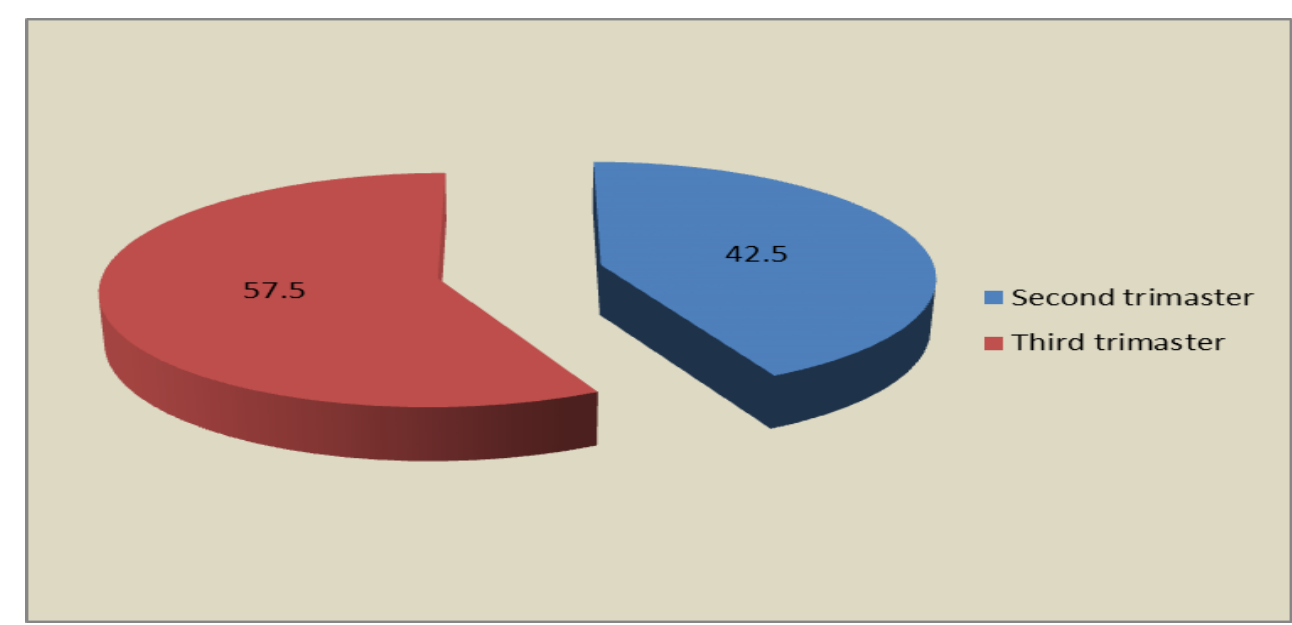

Figure (1): Distribution of studied women regarding gestation of pregnancy $(n=200)$. 


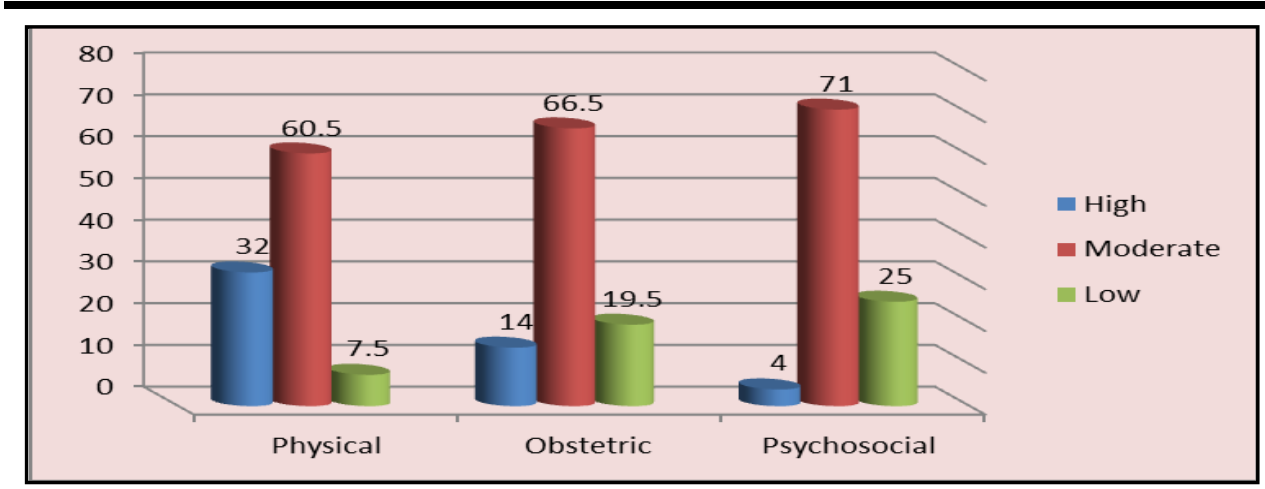

Figure (2): Distribution of factors affecting sleep disturbances during pregnancy among the derailed women. $(n=200)$.

Table (2) Distribution of the studied women according to their various sleep disturbances during pregnancy.

\begin{tabular}{|c|c|c|}
\hline Parameter & No $n=200$ & $\%$ \\
\hline \multicolumn{3}{|l|}{ Subjective sleep quality } \\
\hline $\begin{array}{l}\text { Poor } \\
\text { Average } \\
\text { Good }\end{array}$ & $\begin{array}{c}32 \\
154 \\
14\end{array}$ & $\begin{array}{c}16.0 \\
77.0 \\
7.0\end{array}$ \\
\hline \multicolumn{3}{|l|}{ Sleep latency( minutes) } \\
\hline $\begin{array}{l}\text { Good }(\text { short }<15 \mathrm{~m}) \\
\text { Average }(\text { average } 15-30) \\
\text { Poor }(\text { long }>30)\end{array}$ & $\begin{array}{l}59 \\
51 \\
90\end{array}$ & $\begin{array}{l}29.5 \\
25.5 \\
45.0\end{array}$ \\
\hline \multicolumn{3}{|l|}{ Sleep duration(hours) } \\
\hline $\begin{array}{l}\text { Short }<7 \\
\text { Average } 7-9 \\
\text { Long }>9\end{array}$ & $\begin{array}{c}47 \\
52 \\
101 \\
\end{array}$ & $\begin{array}{l}23.5 \\
26.0 \\
50.5\end{array}$ \\
\hline \multicolumn{3}{|l|}{ Sleep disturbance (present) } \\
\hline $\begin{array}{l}>85 \% \\
75-84 \% \\
65-74 \% \\
<65 \% \\
\end{array}$ & $\begin{array}{l}47 \\
24 \\
36 \\
93\end{array}$ & $\begin{array}{l}23.5 \\
12.0 \\
18.0 \\
46.5\end{array}$ \\
\hline \multicolumn{3}{|l|}{ Sleep disturbances } \\
\hline $\begin{array}{l}\text { Not during the past month } \\
\text { Less than once a week } \\
\text { Once or twice per week } \\
\text { Three or more times a week }\end{array}$ & $\begin{array}{c}0 \\
4 \\
43 \\
153\end{array}$ & $\begin{array}{c}0.0 \\
2.0 \\
21.5 \\
76.5\end{array}$ \\
\hline \multicolumn{3}{|l|}{ Day time dysfunction } \\
\hline $\begin{array}{l}\text { Not during the past month } \\
\text { Less than once a week } \\
\text { Once or twice a week } \\
\text { Three or more times a week }\end{array}$ & $\begin{array}{c}12 \\
155 \\
31 \\
2\end{array}$ & $\begin{array}{c}6.0 \\
77.5 \\
15.5 \\
1.0\end{array}$ \\
\hline
\end{tabular}


Table (3) Distribution of studied women according the relation between sociodemographic characteristics and total sleep quality among the studied women $n=200$.

\begin{tabular}{|c|c|c|c|c|c|c|c|c|}
\hline \multirow{2}{*}{ Parameter } & \multicolumn{2}{|c|}{$\begin{array}{c}\text { Good } \\
\mathbf{n}=\mathbf{2 0 0}\end{array}$} & \multicolumn{2}{|c|}{$\begin{array}{c}\text { Average } \\
\mathbf{n}=\mathbf{2 0 0}\end{array}$} & \multicolumn{2}{|c|}{$\begin{array}{c}\begin{array}{c}\text { Poor } \\
n=200\end{array}\end{array}$} & \multirow[t]{2}{*}{$x^{2}$} & \multirow{2}{*}{ p-value } \\
\hline & No & $\%$ & No & $\%$ & No & $\%$ & & \\
\hline \multicolumn{9}{|l|}{ Age(years) } \\
\hline $\begin{array}{l}<20 \\
20<30 \\
30-40\end{array}$ & $\begin{array}{c}9 \\
16 \\
0\end{array}$ & $\begin{array}{l}4.5 \\
8.0 \\
0.0\end{array}$ & $\begin{array}{c}11 \\
113 \\
4\end{array}$ & $\begin{array}{c}5.5 \\
56.5 \\
2.0\end{array}$ & $\begin{array}{c}1 \\
36 \\
10\end{array}$ & $\begin{array}{c}0.5 \\
18.0 \\
5.0\end{array}$ & 38.99 & $0.00 * *$ \\
\hline \multicolumn{9}{|l|}{ Educational level } \\
\hline $\begin{array}{l}\text { Illiterate } \\
\text { Basic education } \\
\text { Secondary education } \\
\text { University education }\end{array}$ & $\begin{array}{c}1 \\
1 \\
11 \\
12\end{array}$ & $\begin{array}{l}0.5 \\
0.5 \\
5.5 \\
6.0\end{array}$ & $\begin{array}{c}2 \\
7 \\
50 \\
69\end{array}$ & $\begin{array}{c}1.0 \\
3.5 \\
25.0 \\
34.5\end{array}$ & $\begin{array}{c}10 \\
1 \\
18 \\
18\end{array}$ & $\begin{array}{l}5.0 \\
0.5 \\
9.0 \\
9.0\end{array}$ & 23.55 & $0.001 * *$ \\
\hline \multicolumn{9}{|l|}{ Occupation } \\
\hline $\begin{array}{l}\text { Working } \\
\text { House wife }\end{array}$ & $\begin{array}{c}7 \\
18\end{array}$ & $\begin{array}{l}3.5 \\
9.0\end{array}$ & $\begin{array}{l}35 \\
93\end{array}$ & $\begin{array}{l}17.5 \\
46.5\end{array}$ & $\begin{array}{c}9 \\
38\end{array}$ & $\begin{array}{c}4.5 \\
19.0\end{array}$ & 1.3 & 0.52 \\
\hline \multicolumn{9}{|l|}{ Nature of work } \\
\hline $\begin{array}{l}\text { Office work } \\
\text { Hard work }\end{array}$ & $\begin{array}{l}7 \\
3\end{array}$ & $\begin{array}{l}3.5 \\
1.5\end{array}$ & $\begin{array}{l}13 \\
10\end{array}$ & $\begin{array}{c}6.5 \\
5\end{array}$ & $\begin{array}{c}10 \\
8\end{array}$ & $\begin{array}{l}5 \\
4\end{array}$ & 12.84 & $0.012 *$ \\
\hline \multicolumn{9}{|l|}{ Residence } \\
\hline $\begin{array}{l}\text { Rural } \\
\text { Urban }\end{array}$ & $\begin{array}{c}19 \\
6\end{array}$ & $\begin{array}{l}9.5 \\
3.0\end{array}$ & $\begin{array}{l}81 \\
47\end{array}$ & $\begin{array}{l}40.5 \\
23.5\end{array}$ & $\begin{array}{c}38 \\
9\end{array}$ & $\begin{array}{c}19.0 \\
4.5\end{array}$ & 5.61 & $0.06 *$ \\
\hline \multicolumn{9}{|l|}{ Type of family } \\
\hline $\begin{array}{l}\text { Nuclear family } \\
\text { Extended family }\end{array}$ & $\begin{array}{l}14 \\
11\end{array}$ & $\begin{array}{l}7.0 \\
5.5\end{array}$ & $\begin{array}{l}62 \\
66\end{array}$ & $\begin{array}{l}31.0 \\
33.0\end{array}$ & $\begin{array}{l}24 \\
23\end{array}$ & $\begin{array}{l}12.0 \\
11.5\end{array}$ & 0.5 & 0.77 \\
\hline
\end{tabular}

*Statistically significance $(\mathrm{p}<0.05) \quad * *$ Highly statistically significance $(\mathrm{p}<0.001)$ 
Table (4) the relation between total sleep quality and factors affecting sleep disturbances during pregnancy among pregnant women $n=200$.

\begin{tabular}{|c|c|c|c|c|c|c|c|c|}
\hline \multirow{2}{*}{ Factors } & \multicolumn{2}{|c|}{ Good } & \multicolumn{2}{|c|}{ Average } & \multicolumn{2}{|c|}{ Poor } & \multirow{2}{*}{$\mathbf{x} 2$} & \multirow{2}{*}{$\begin{array}{l}\text { p- } \\
\text { value }\end{array}$} \\
\hline & No & $\%$ & No & $\%$ & No & $\%$ & & \\
\hline \multicolumn{9}{|c|}{ physical factor } \\
\hline $\begin{array}{l}\text { Low } \\
\text { Moderate } \\
\text { High }\end{array}$ & $\begin{array}{c}5 \\
17 \\
3\end{array}$ & $\begin{array}{l}2.5 \\
8.5 \\
1.5\end{array}$ & $\begin{array}{c}6 \\
77 \\
45\end{array}$ & $\begin{array}{c}3.0 \\
38.5 \\
22.5\end{array}$ & $\begin{array}{c}4 \\
27 \\
16\end{array}$ & $\begin{array}{c}2.0 \\
13.5 \\
8.0\end{array}$ & 10.51 & $0.033^{*}$ \\
\hline \multicolumn{9}{|c|}{ Obstetrics factors } \\
\hline $\begin{array}{l}\text { Low } \\
\text { Moderate } \\
\text { High }\end{array}$ & $\begin{array}{c}6 \\
16 \\
3 \\
\end{array}$ & $\begin{array}{l}3.0 \\
8.0 \\
1.5\end{array}$ & $\begin{array}{l}27 \\
84 \\
17\end{array}$ & $\begin{array}{c}13.5 \\
42.0 \\
8.5\end{array}$ & $\begin{array}{c}6 \\
33 \\
8\end{array}$ & $\begin{array}{c}3.0 \\
16.5 \\
4.0\end{array}$ & 2.08 & 0.72 \\
\hline \multicolumn{9}{|c|}{ Psycho social factors } \\
\hline $\begin{array}{l}\text { Low } \\
\text { Moderate } \\
\text { High }\end{array}$ & $\begin{array}{c}9 \\
16 \\
0\end{array}$ & $\begin{array}{l}4.5 \\
8.0 \\
0.0\end{array}$ & $\begin{array}{c}34 \\
89 \\
5\end{array}$ & $\begin{array}{c}17.0 \\
44.5 \\
2.5\end{array}$ & $\begin{array}{c}7 \\
37 \\
3\end{array}$ & $\begin{array}{c}3.5 \\
18.5 \\
1.5\end{array}$ & 5.53 & 0.23 \\
\hline
\end{tabular}

*Statistically significance $(\mathbf{p}<0.05) \quad * *$ highly statistically significance $(\mathbf{p}<0.001)$

Table (5) Distribution of studied women according comparison between second and third trimester $n=200$.

\begin{tabular}{|c|c|c|c|c|c|c|}
\hline Parameters & \multicolumn{2}{|c|}{ Second trimester } & \multicolumn{2}{|c|}{ Third trimester } & \multirow[t]{2}{*}{$\mathbf{x} 2$} & \multirow[t]{2}{*}{ p-value } \\
\hline Insomnia level & No & $\%$ & No & $\%$ & & \\
\hline $\begin{array}{l}<9 \text { clinically } \\
\text { insignificance } \\
\geq 9 \text { clinically } \\
\text { significance }\end{array}$ & $\begin{array}{l}13 \\
72\end{array}$ & $\begin{array}{c}6.5 \\
36.0\end{array}$ & $\begin{array}{c}12 \\
103\end{array}$ & $\begin{array}{c}6.0 \\
51.5\end{array}$ & 4.05 & $0.03 *$ \\
\hline \multicolumn{7}{|c|}{ Epworth scale day time sleep } \\
\hline $\begin{array}{l}\text { Mild sleepiness } \\
\text { Moderate sleepiness } \\
\text { Severe } \\
\text { sleepiness }\end{array}$ & $\begin{array}{c}67 \\
14 \\
4\end{array}$ & $\begin{array}{c}33.5 \\
7.0 \\
2.0\end{array}$ & $\begin{array}{c}100 \\
14 \\
1\end{array}$ & $\begin{array}{c}50.0 \\
7.0 \\
0.5\end{array}$ & 3.9 & 0.142 \\
\hline \multicolumn{7}{|l|}{ Leg cramps } \\
\hline $\begin{array}{l}\text { Mild } \\
\text { Moderate } \\
\text { Severe }\end{array}$ & $\begin{array}{l}37 \\
31 \\
17\end{array}$ & $\begin{array}{c}18.5 \\
15.5 \\
8.5\end{array}$ & $\begin{array}{c}38 \\
72 \\
5\end{array}$ & $\begin{array}{c}19.0 \\
36.0 \\
2.5\end{array}$ & 18.8 & $0.000 * *$ \\
\hline \multicolumn{7}{|l|}{ Snoring } \\
\hline $\begin{array}{l}\text { More than three } \\
\text { times } \\
\text { Twice } \\
\text { Once } \\
\text { Nothing }\end{array}$ & $\begin{array}{c}68 \\
0 \\
5 \\
12\end{array}$ & $\begin{array}{c}34 \\
0 \\
2.5 \\
6\end{array}$ & $\begin{array}{c}73 \\
5 \\
16 \\
21\end{array}$ & $\begin{array}{c}36.5 \\
2.5 \\
8 \\
10.5\end{array}$ & 9.09 & .028 \\
\hline
\end{tabular}




\begin{tabular}{|c|c|c|c|c|c|c|}
\hline $\begin{array}{l}\text { Good } \\
\text { Average } \\
\text { Poor }\end{array}$ & $\begin{array}{l}10 \\
62 \\
13\end{array}$ & $\begin{array}{c}5 \\
31 \\
6.5 \\
\end{array}$ & $\begin{array}{l}15 \\
66 \\
34 \\
\end{array}$ & $\begin{array}{l}7.5 \\
33 \\
17 \\
\end{array}$ & 6.14 & $0.04 *$ \\
\hline \multicolumn{7}{|c|}{ Short sleep duration } \\
\hline $\begin{array}{l}>7 \\
6-7 \\
5-6 \\
<5\end{array}$ & $\begin{array}{l}13 \\
10 \\
46 \\
16\end{array}$ & $\begin{array}{c}6.5 \\
5 \\
23 \\
8\end{array}$ & $\begin{array}{c}15 \\
9 \\
55 \\
36\end{array}$ & $\begin{array}{c}7.5 \\
4.5 \\
27.5 \\
18\end{array}$ & 6.28 & $0.04 *$ \\
\hline
\end{tabular}

\section{Discussion}

Sleep disturbances has become a major public health because of its detrimental effects on cognitive functioning over time, accidents and errors in the workplace, and alterations in metabolic and endocrine function of individuals. Increasing evidence also suggests that sleep disturbances may increase mortality (Jen Jen Chang et al., 2010)Sleep disturbances during pregnancy are associated with poor pregnancy out comes for both mother and fetus. There are emerging associations between maternal sleep and several major risk factors for stillbirth, maternal obesity, preeclampsia, gestational diabetes, and intra-uterine growth restriction. More pain and discomfort during labor, higher rates preterm delivery, greater likelihood of caesarean deliveries and postpartum depression are associated with impaired maternal sleep (Ko et al .,2013).This study aimed to.........

\section{Aim of the study is to:}

1- Identify pattern of sleep disturbances during pregnancy among primigravidea women.

2- Identify possible contributing factors to sleep disturbances during pregnancy among primigravidea women .

Regarding the characteristics of the studied women, the findings of the present study revealed that more than three quarters of the studied women's age ranged from 20 - 30 years old with mean age $22.3+2.7$ years. This may be due to all of the studied women were primigravidea. This finding is in accordance with Samar and Rasha (2012) who found that more than one half of women aged less than 25years and more than one third, aged between 25 to less than 35 years. As regards theduration of pregnancy, the findings of the present study showed that more than half of women were in the third trimester with mean gestational age $32.15 \pm 6.6$ weeks. This finding is supported byKeefe and Onge (2015) who found that two thirds of the studied sample were in the third trimester. Hutchison et al., (2012) mentioned that all studied sample were in the third trimester with a median gestation of 36 weeks.

Concerning total factors affecting women's sleep during pregnancy, the findings of the present study illustrated that, two thirds were moderately affected by obstetric factors, less than two thirds of studied women moderately affected by physical factors and more than two thirds of studied woman's sleep moderately affected by psycho social factors. These findings are in accordance with Soner et al., (2014) whofound that sleep patterns and sleep quality in pregnant women are disturbed by problems, such as increasing abdominal discomfort as a result of the pressure to the diaphragm made by growing fetus, nocturia, back pain and leg cramps.

Moreover, Kumer et al., (2015) found that women during the third trimester of pregnancy experienced 
various levels of psychological difficulties than non-pregnant women of similar age group and other sociodemographic status. While, the pregnant women during third trimester experienced more somatization, interpersonal sensitivity, depression, anger hostility, phobic anxiety, psychotism and disturbance in sleep and appetite than non-pregnant women.

The findings of the present study demonstrated that more than half of studied women are strongly affected in their sleep by frequent micturation at night, uncomfortable position during sleep, back pain, heart burn, insomnia and leg cramps. This may be because pregnancy physical changes cause significant discomfort and can impair the ability to fall asleep. This finding is congruent withsamar and Rasha.( 2012) whorevealed that nocturnal awakening was the most reported pattern of sleep disturbances among pregnant woman followed by insomnia, lack of dream sleep and light sleep. Frequent nocturia, abdominal discomfort, breathing disorders, low backache and restless leg syndrome were the most given reasons for sleep disturbances among the suffered study women.

In the same context, Sousa et al., (2015) mentiond that women in the second trimester of pregnancy complain of low back pain. Moreover Aynur et al., (2012) found that more than one half of the pregnant women participating in this study experienced insomnia. Also, it was revealed that the reasons for insomnia detected in this study in the frequent visits to the toilet, not finding a comfortable position while sleeping, and restless legs.

As regard total various sleep disturbances as a component of Pittsburg scale, the findings of the present study demonstrated that more than three quarters of the studied women have average subjective sleep quality, sleep disturbances three or more times a week, day time dysfunction. About half of women have long sleep latency, long sleep duration and low sleep efficacy. Mean while all of the studied women don't tak medication to help to sleep during the past month. These findings are supported by Nevertity, (2015) who found that the studied women have average subjective sleep quality, long sleep latency, long sleep duration, low sleep efficacy, sleep disturbances three or more times per week, don't tak medication to help to sleep during the past month and day time dysfunction $(52.5 \%, 38.5 \%, 63 \%, 42.5 \%$, $53.5 \%, 88.5 \%$, and $50.5 \%$ ) respectively.

As regards the relation between total sleep quality and socio demographic characteristics, the findings of the present study reported a highly statistical significance difference $(p<0.01)$ between total sleep quality and age. This finding is agreed with GörevlisiNihal , (2011) who found that $86 \%$ of the pregnant women involved in their study have bad sleep quality. It was determined that sleep quality in pregnant women is related with age $(\mathrm{p}<0.05)$.

Concerning relation between total sleep quality and gestational age, the findings of the present study showed a statistically significant difference $(p<0.05)$ between total sleep quality and gestational age. This may be due to pressure on the bladder, as a result of increasing uterine size, frequent urination, heart burn, backache, itching, increasing fetal movements, and physical changes cause discomfort and can impair ability to fall to sleep. This finding is supported by Hutchison (2012) who showed that a reduction in maternal sleep quality in the third trimester compared with before pregnancy. 
Concerning relation between total sleep quality and factors affecting sleep disturbances, the findings of the present study showed that a statistically significant difference $(p<0.05)$ between total sleep quality and physical factors affecting sleep disturbances. This may be due to general physical discomfort, frequent urination, back and neck pain, vivid dreams, nasal congestion, leg cramps, fetal movements, and uterine contractions. These findings agree with Mindelland Jacobson, (2010) who revealed that a large percentage of the women experienced sleep disturbances during pregnancy; these problems included frequent night waking, difficulty falling asleep, and symptoms of sleep apnea.

The finding of the present study showed a statistically significant difference between insomnia and obesity degree during pregnancy. This finding disagree with Kennellyetal. (2011) who found no relationship between sleep habit and BMI.

As regards the comparison between second and third trimesters sleep as regards averages disturbance the findings of the present study demonstrated that sleep disturbances occur in the third trimester more than second trimester. This mean that there were statistical difference $(p<0.05)$ between second and third trimester as regards insomnia, leg cramps, snoring, total sleep quality score and short sleep duration. This finding are supported by ALLawati (2009) who reported that during the third trimester nearly $40 \%$ of women reported sleeping on average less than 7 hours per night, and more than $16 \%$ reported frequent snoring.
Conclusion

- In the light of results of the present study, it was concluded that poor sleep quality was prevalent among healthy primigravida women during their pregnancy. While, insomnia, snoring, breathing disturbances, day time sleepiness and leg cramps are the most common pattern of sleep disturbances. And it was significantly related to demographic characteristics such as: age, educational levels, nature of work, residence, gestational age of pregnancy and obesity degree. As well as adverse obstetrical disorders, physical and psychosocial factors associated with their pregnancy.

\section{Recommendations}

The present study recommended that:

- Discussing factors that lead to sleep disturbances should be included in routine antenatal care for pregnant women.

- Educate women about how to improve sleep pattern during pregnancy

\section{References}

Al Lawati NM, Patel SR and Ayas NT (2009): Epidemiology, risk factors, and consequences of obstructive sleep apnea and short sleep duration. ProgCardiovasc Dis; 51:285-9.

Aynur K, Sermin T and Bahtışen $\mathrm{K}$ (2012):VefaKuçuk Health College, Nevşehir Unıversity, Nevşehir, Turkey Health College, Inonu University, 441280 Malatya, The 
Scientific World Journal Volume 2012 (2012), Article ID 197093, 8 pagesReceived 23 November 2011; Accepted 24 January 2012 http://dx.doi.org/10.1100/2012/19709 $\underline{3}$

Carole, S. (2007): The Pittsburgh Sleep Quality Index (PSQI).The Hartford Institute for Geriatric Nursing, College of Nursing, New York University. 6 (1)

Da Costa D, Dritsa M, Verreault N, Balaa C, Kudzman J and Khalifé S (2010): Sleep problems and depressed mood negatively impact health-related quality of life during pregnancy. Arch WomensMent Health.; 13:249-57

Douglas W. Levine, Megan A. Lewis, Daniel F. Kripke and Robert M. Kaplan, Sally A. Shumaker, Deborah J. Bowen (2003): Reliability and Validity of the Women's Health Initiative Insomnia Rating Scale the American Psychological Association, Vol. 15, No. 2, 137-148 10403590/03/\$12.00 DOI: $10.1037 / 1040-$ 3590.15.2.137

Gabriel, N.; Monica, L.; Márcia, G. and Sergio, T (2010): Sleep impairment during pregnancy: Possible implications on mother-infant relationship. Medical. 75 (6): 578582.

Golmakani N, SeyedAhmadiNejad FS, Shakeri MT, Asghari Pour N (2015): Comparing the Effects of Progressive Muscle Relaxation and Guided Imagery on Sleep Quality in Primigravida Women Referring to Mashhad Health Care Centers -1393. Journal of Midwifery and Reproductive Health. ; 3(2): 335-342.

Görevlisi N (2011): Pregnancy and sleep quality Journal of Turkish Society of
Obstetrics and Gynecology; Vol: 8 Issue: 3 Pages: 181- 187

Hutchison L. Peter R. Lesley M. Cowan M., Alistair W. John $\mathrm{M}$ and Edwin (2012):A .A postal survey of maternal sleep in late pregnancy 12 ; 144.

Jen Jen Chang, PhD, Grace W, Pien MD, MS, Stephen P, Duntley MD, George A and Macones MD (2010): Sleep Deprivation during Pregnancy and Maternal and Fetal Outcomes: Is There a Relationship? 51:285-93.

Johns M. (2005): A new method for measuring daytime sleepiness: The Epworth sleepiness scale. Sleep; 14 (6):540-545.

Keeffe M and St-Onge MP (2015): Sleep duration and disorders in pregnancy: implications for glucose metabolism and pregnancy outcomesFisioter. mov. vol.28 no. 2 Curitiba.

Kempler L,Louise S and Delwyn B. (2012):Sleep education during pregnancy for newmothersReceived: 4 December Ac cepted: 7 December Published: 17 De cember DOI: 10.1186/1471-2393-12155

Kennelly MM, Fallon A, Farah N, Stuart B, Turner MJ (2011): Effects of body mass index on sleep patterns during pregnancy. J ObstetGynaecol.; 31(2):125-127.

Ko HS, Kim MY, Kim YH, Lee J, Park YG, Moon HB, Kil KC, Lee G, Kim SJ and Shin JC (2013): Obstructive sleep apnea screening and perinatal outcomes in Korean pregnant women. Arch Gynecol Obstet.; 287(3):429-433. 
Kumar Nayak1, Rinku Poddar2, Dr. MasroorJahan (2015): Psychological Problems during Advance Stage of Pregnancy The International Journal ofindian Psychology | ISSN 23485396 Volume 2, Issue 2, Paper ID: B00313V2I22015 http://www.ijip.

Mindell JA and Jacobson, (2010): Sleep Disturbances During Pregnancy Volume 29, Number 6.

Nevertity Hassan Zaky (2015): The Relationship between Quality of Sleep during Pregnancy and Birth Outcome among Primiparae2320-1940 Volume 4, Issue 5 Ver. I (Sep. - Oct. 2015), PP 90-101 www.iosrjournals.org DOI: 10.9790/1959-045190101 www.iosrjournals.org 90.

O'Brien L.Bullough A.Owusu J. Tremblay K.Brincat C.Kalbfleisch J. and Chervin RD (2014): PregnancyOnset Habitual Snoring, GestationalHypertension, and Preeclampsia: Prospective Cohort Study. Am J Obstet, Gynecol.; (4):839.

Philip P.Sagaspe P. Leger D. Taillard J. Bayon V. Chaumet G (2010: Might the Berlin Sleep Questionnaire applied to bed partners be used to screen sleep apneic patients?;11(5):479-483. doi: $10.1016 / j$.

Rezaei E. Moghadam Z. Nejat S. and Dehghannayeri N. (2014): The impact of sleep healthy behavior education on the quality of life in the pregnant women with sleep disorder: A randomized control trial,Iran J Nursing Midwifery Res. Sep-Oct; 19(5): 508-516.

Samar k and Rasha M (2012): Patterns of Sleep Disturbances among Healthy Nulliparous Women. Journal of American Science; 8(4):172-178.

Soner O, Selçuk K, AvciAhmet F, DalgaciSalih S, (2014): Factors affecting general sleep pattern and quality of sleep in pregnant women; 12: 1-5.

SousaV, Silvia O, Carla M , Elizabel S (2015) : Quality of sleep in pregnant woman with low back painoriginal article

vol.28 no. 2 http://dx.doi.org/10.1590/ 0103-5150.028.002.AO12

Spielman A. Yang C.Glovinsky P.Sateia MJ and Buysse D. (2014): Insomnia: Sleep restriction therapy. In: Insomnia Diagnosis and Treatment, London .p.277.

Suman K (2014): An exploratory study to assess the sleep disturbances in pregnant women attending antenatal OPD of a selected hospital, Ludhiana International Journal of Development ResearchVol. 4(11): 2503-2506. 